\title{
PAI-1 is a Critical Upstream Regulator of the TGF- $\beta 1 /$ EGF-Induced Invasive Phenotype in Mutant p53 Human Cutaneous Squamous Cell Carcinoma
}

\author{
Cynthia E. Wilkins-Port, ${ }^{1}$ Craig E. Higgins, ${ }^{1}$ Jennifer Freytag, ${ }^{1}$ Stephen P. Higgins, ${ }^{1}$ \\ J. Andrew Carlson, ${ }^{2}$ and Paul J. Higgins ${ }^{1,2}$ \\ ${ }^{1}$ Center for Cell Biology and Cancer Research, Albany Medical College, 47 New Scotland Avenue, Albany, NY 12208, USA \\ ${ }^{2}$ Department of Pathology and Laboratory Medicine, Albany Medical College, 47 New Scotland Avenue, Albany, NY 12208, USA
}

Received 17 November 2006; Accepted 17 January 2007

Recommended by Hasan Mukhtar

The emergence of highly aggressive subtypes of human cutaneous squamous cell carcinoma (SCC) often reflects increased autocrine/paracrine TGF- $\beta$ synthesis and epidermal growth factor receptor (EGFR) amplification. Cooperative TGF- $\beta /$ EGFR signaling promotes cell migration and induces expression of both proteases and protease inhibitors that regulate stromal remodeling resulting in acquisition of an invasive phenotype. TGF- $\beta 1+$ EGF stimulation increases the production of several matrix metalloproteinases (MMPs) in human SCC. Among the most prominent is MMP-10 which is known to be elevated in SCC in situ. Activation of stromal plasminogen appears to be critical in triggering downstream MMP activity. Paradoxically, PAI-1, the major physiological inhibitor of plasmin generation, is also up-regulated under these conditions and is an early event in progression of incipient epidermal SCC. A model is proposed in which TGF- $\beta 1+$ EGF-dependent MMP-10 elevation directs focalized matrix remodeling events that promote epithelial cell plasticity and tissue invasion. Increased PAI-1 expression serves to temporally and spatially modulate plasmin-initiated pericellular proteolysis, further facilitating epithelial invasive potential. Defining the complex signaling mechanisms that maintain this elegant balance is critical to developing potential therapeutics for the treatment of human cutaneous malignancies.

Copyright (c) 2007 Cynthia E. Wilkins-Port et al. This is an open access article distributed under the Creative Commons Attribution License, which permits unrestricted use, distribution, and reproduction in any medium, provided the original work is properly cited.

\section{HUMAN EPITHELIAL SKIN CANCER PROGRESSION}

Cutaneous cancer is the most common human malignant disease [1]; in North America alone, $>50 \%$ of all neoplasms arise in the skin [2]. The development and progression of epithelial skin tumors is causally linked to ultraviolet (UV) radiation exposure, with UV-B "signature" base changes $(\mathrm{C} \rightarrow \mathrm{T}$ or $\mathrm{CC} \rightarrow \mathrm{TT}$ ) frequently mapping to codons 177 (basal cell carcinoma) and 278 (squamous cell carcinoma (SCC)) in the tumor suppressor p53 gene $[3,4]$. Indeed, UV-associated p53 mutations regularly occur in the solar radiation-induced premalignancy actinic keratosis. Approximately $10 \%$ of these precancerous lesions progress to SCC and it has been estimated that $60 \%$ of all SCC arise within actinic keratoses [46].

The progression sequence for cutaneous cancers may vary between the human disease and its corresponding mouse models, although several genetic events are common to both $[2,3,5-7]$. Transition of a normal keratinocyte to an initiated pre- or early malignant phenotype for example often involves p53 inactivation, ras gene mutation and amplified ras expression. These changes frequently accompany growth of lesional subsets in both actinic keratosis and SCC [5-7]. Recent findings suggest that the emergence of highly aggressive subtypes of SCC (including the lethal spindle cell tumor) and the development of metastatic variants are causally linked to overexpression of transforming growth factor- $\beta 1$ (TGF- $\beta 1$ ) $[2,8-10]$. Elevated autocrine and/or paracrine production of TGF- $\beta 1$, in fact, typifies advanced pathologies in both mouse and human SCC $[8,10]$. Despite high levels of TGF- $\beta$ in the immediate tumor microenvironment, at least some malignant epithelial cells become refractory to the normal program of proliferative arrest initiated by TGF- $\beta$ which is likely a consequence of 


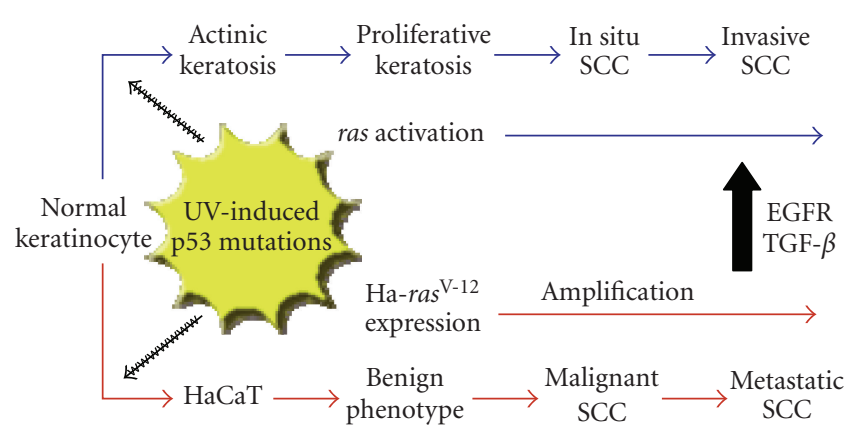

Figure 1: Genetic events associated with human cutaneous SCC progression in vivo and in the HaCaT keratinocyte model system in vitro. Additional similarities are discussed in the text as well as in $[2,3,21]$.

transformation-associated reductions in either TGF- $\beta$-RII or Smad-4 levels, or both [10-12]. In experimental models of skin carcinogenesis, moreover, resistance to TGF- $\beta 1$-induced growth suppression is often coupled with epidermal growth factor receptor (EGFR) amplification, particularly during the later stages of tumor progression [13-17]. Indeed, cutaneous SCCs frequently exhibit constitutive activation of the EGFR as a result of receptor amplification and/or autocrine ligand release [18]. The subsequent reprogramming of gene expression in the transformed keratinocyte initiates and perpetuates the TGF- $\beta 1$-induced pro-oncogenic switch to a "plastic" phenotype, resulting in the transition from a relatively indolent to a highly aggressive and invasive epithelial malignancy $[8,19,20]$.

\section{DETERMINANTS OF CELLULAR PLASTICITY IN TRANSFORMED HUMAN KERATINOCYTES}

The immortalized adult human keratinocyte cell line HaCaT-II4 is particularly suited for assessment of molecular mechanisms associated with epithelial tumor cell plasticity (reviewed in [13]). HaCaT-II4 cells harbor mutations that mirror those associated with cutaneous malignant transformation. These include UV-specific mutations in both alleles of the p53 gene (resulting in loss of p53 function [3]), increased levels of an activated Ha-ras gene, and chromosomal aberrations often typical of SCC (e.g., loss of 3p and 9p, gain of 3q) $[2,3,21]$ (Figure 1).

HaCaT-II4 cell stimulation with a combination of TGF$\beta 1$ and EGF, designed to mimic the elevated TGF- $\beta 1$ expression/amplified EGFR signaling that frequently accompanies SCC progression in vivo, promotes a phenotypic transition that involves the loss of E-cadherin from cell-cell junctions, actin microfilament remodeling (Figure 2), increased motility, and significantly enhanced pericellular proteolytic capability $[22,23]$.

Stromal proteolysis by transformed keratinocytes is often initiated by conversion of epidermal matrix plasminogen to the broad-spectrum protease plasmin via urokinase
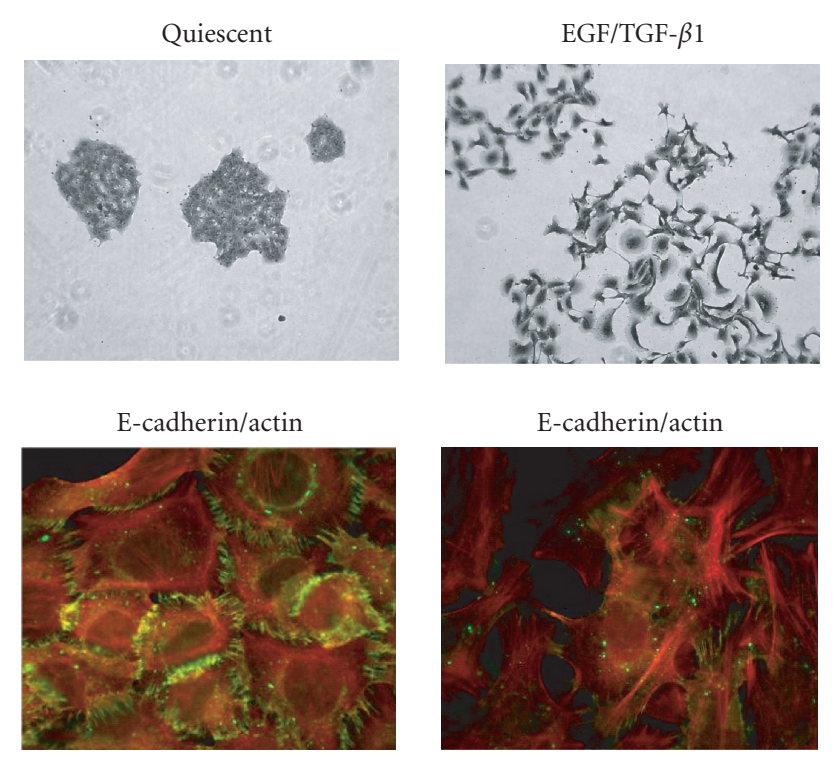

FIgure 2: HaCaT-II4 keratinocytes initiate a prominent "scattering" response after a $24-48$ hour exposure to EGF/TGF- $\beta 1$. Colony dispersal (top panels) reflects the early and significant loss of Ecadherin-positive cell-cell junctions (green) and marked reorganization in the actin microfilament system (red) (bottom panels). Such morphologic restructuring is a hallmark of epithelial plasticity initiated by TGF- $\beta$ and EGF family members.

plasminogen activator receptor (uPAR)-bound uPA [24-26]. Plasmin generation accompanies cooperative TGF- $\beta /$ EGFR signaling during epidermal tumor progression and appears to be a critical event in the downstream activation of a complex and highly interdependent, matrix metalloproteinase (MMP) cascade (reviewed in [23]). Microarray profiling of HaCaT-II4 cells stimulated with both TGF- $\beta 1$ and EGF confirmed, in fact, that uPA, uPAR, and MMP expression levels were significantly upregulated (e.g., Figure 3). Transcripts encoding plasminogen activator inhibitor type1 (PAI-1; SERPINE1), the major physiological regulator of plasmin-based pericellular proteolysis, were also significantly increased. Indeed, elevated PAI-1 tumor levels signal a poor prognosis and reduced disease-free survival in patients with breast, lung, ovarian, and oral SCC [26, 27]. Mouse modeling and genetic studies clearly implicate PAI-1 as an important determinant in cutaneous tumor invasion and the associated angiogenic response. This serine protease inhibitor maintains an angiogenic "scaffold," stabilizes nascent capillary vessel structure, and regulates tumor cell invasion through precise regulation of the peritumor proteolytic microenvironment [26, 28-30]. PAI-1 upregulation is, in fact, an early event in the progression of incipient epidermal SCC, where it often localizes in tumor cells and myofibroblasts at the invasive front (Figure 4), and most importantly is a tumor marker with significant prognostic value [27, 31-33]. Furthermore, identification of PAI-1 in SCC-proximal stromal 
myofibroblasts implies a more global involvement in modulating cellular invasive potential, [34-36] with complex autocrine and paracrine loops dictating the varied effects of this SERPIN on individual elements (neoplastic, endothelial, and inflammatory cells) within the tumor microenvironment.

\section{GROWTH FACTOR-INITIATED EPITHELIAL PLASTICITY ELICITS A PROGRAM OF MATRIX REMODELING}

Treatment of HaCaT-II4 cells with TGF- $\beta 1$ and EGF promotes a plastic transition typical of late-stage SCC progression (Figure 2). Part of this response most likely reflects the transcriptional consequences associated with deregulated growth factor signaling (e.g., Figure 3) [37-40]. TGF$\beta 1$ stimulates synthesis of stromal components (e.g., fibronectin, collagen, laminin), thereby supporting the maintenance of matrix integrity; this growth factor, however, also increases expression of several extracellular matrixdegrading MMPs, including MMP-1, -2, -3, -9, -10, -11, -13 , and 21 [41-47]. Unlike the normal epithelium, where TGF- $\beta 1$ upregulates collagen synthesis and represses collagenase proteolysis, TGF- $\beta 1$ usually decreases collagen synthesis and induces collagenase activity in malignant cells, suggesting that transformed epithelia exhibit an altered response to TGF- $\beta 1$ [48-51]. EGF stimulation similarly induces expression of several MMPs [52-54]. Consequently, a TGF$\beta 1$-enriched tumor microenvironment coupled with amplified EGFR levels and/or signaling correlates strongly with the increased expression of MMP-2, -7, -9, 10, -11, and -13 $[17,55]$ and is frequently associated with advanced pathological stages in human SCC. The expression of MMP-10 (stromelysin-2) following costimulation of HaCat-II4 cells with TGF- $\beta 1$ and EGF is particularly significant $[22,23]$. MMP-10 is generally restricted to epithelial cells $[46,56]$ and has broad substrate specificity, including as targets the proMMPs-1, $-7,-8,-9$, and -13 , collagens types III, IV, and V, gelatin, elastin, fibronectin, proteoglycans, and laminin [25, 57]. MMP-10 is not detectable in normal intact skin [46]. It is however, expressed during cutaneous injury repair where it localizes to migrating keratinocytes at the wound edge, suggesting that MMP-10 facilitates invasive behavior [46]. Indeed, appreciable levels of MMP-10 are evident in SCC of the head and neck, esophagus, oral cavity, and skin, as well as in recurrences of nonsmall cell lung cancer where it likely regulates basement membrane degradation and stromal dissemination $[55,58-64]$. Notably, TGF- $\beta 1 /$ EGF-dependent upregulation of MMP-10 in HaCaT-II4 cells is coincident with enhanced collagen gel invasion (Figure 5) and the development of an acute collagenolytic phenotype that is sensitive to components of the plasminogen activation system, including PAI-1 [22, 23]. While the actual involvement of MMP-10 in late-stage tumor progression remains to be clarified, MMP10 can "superactivate" collagenase I (MMP-1) resulting in a 10 -fold increase in specific activity when compared to MMP1 activation by plasmin alone [56]. Collectively, these findings support a model in which TGF- $\beta 1 /$ EGF-initiated MMP10 upregulation and its plasmin-dependent activation lead to

\begin{tabular}{|l|c|c|}
\hline Upregulated genes & & -+ \\
\hline PAI-1 & 13.54 & \\
PAI-2 & 9.76 & \\
Maspin & 2.08 & \\
uPAR & 5.17 & \\
MMP1 & 3.51 & \\
MMP2 & 2.01 & \\
Cyclin D1 & 2.81 & \\
$\beta$-catenin & 2.9 & \\
Integrin $\alpha 2$ & 2.77 & \\
Integrin $\alpha 3$ & 2.81 & \\
Integrin $\alpha 4$ & 12.05 & \\
Integrin $\alpha 6$ & 3.7 & \\
Integrin $\alpha$ V & 2.75 & \\
BCL2L1 & 2.76 & \\
v-Raf & 3.49 & \\
Ras GAP & 3.25 & \\
VEGF & & \\
\hline Downregulated genes & & \\
\hline TNF & & \\
\hline Min & & \\
\hline
\end{tabular}

Figure 3: Example of a selected cluster of TGF- $\beta 1+$ EGF-induced genes in HaCaT-II4 human SCC cells. PAI-1 is the highest upregulated transcript in the subset illustrated. (13.4-fold assessed 6 hours after growth factor stimulation). MMP-1 and MMP-2 are also significantly increased in response to TGF- $\beta 1+\mathrm{EGF}$ as is the urokinase plasminogen activator receptor ( $\mathrm{UPAR}$ ). The 5 -fold induction of uPA mRNA is not shown. Numbers for the individual upregulated expressed genes indicate the fold increase for TGF- $\beta 1+\mathrm{EGF}-$ stimulated cells compared to unstimulated keratinocytes. The colorized platform serves to provide a visual indicator of the microarray data with green signal corresponding to minimal or nonexpressing status while red signal is indicative of high-level transcript induction.

the degradation of extracellular matrix components directly, as well as indirectly by its ability to trigger MMPs-1, $-7,-8$, -9 , and -13 activities (Figure 6). Subsequently, these downstream proteases target stromal substrates, particularly collagens and additional pro-MMPs in the tumor microenvironment. The resultant feedback loop generated through elevation of MMP-10 levels therefore supports focalized extracellular matrix remodeling which promotes the acquisition of cellular plasticity and tumor cell invasion. Most importantly, this highly interactive plasmin-initiated, pericellular proteolytic cascade is finely "titrated" both temporally and spatially by PAI-1, highlighting the potential therapeutic value of manipulating PAI-1 expression in the treatment of human cutaneous malignancies $[13,22,23,29,30,65]$. 

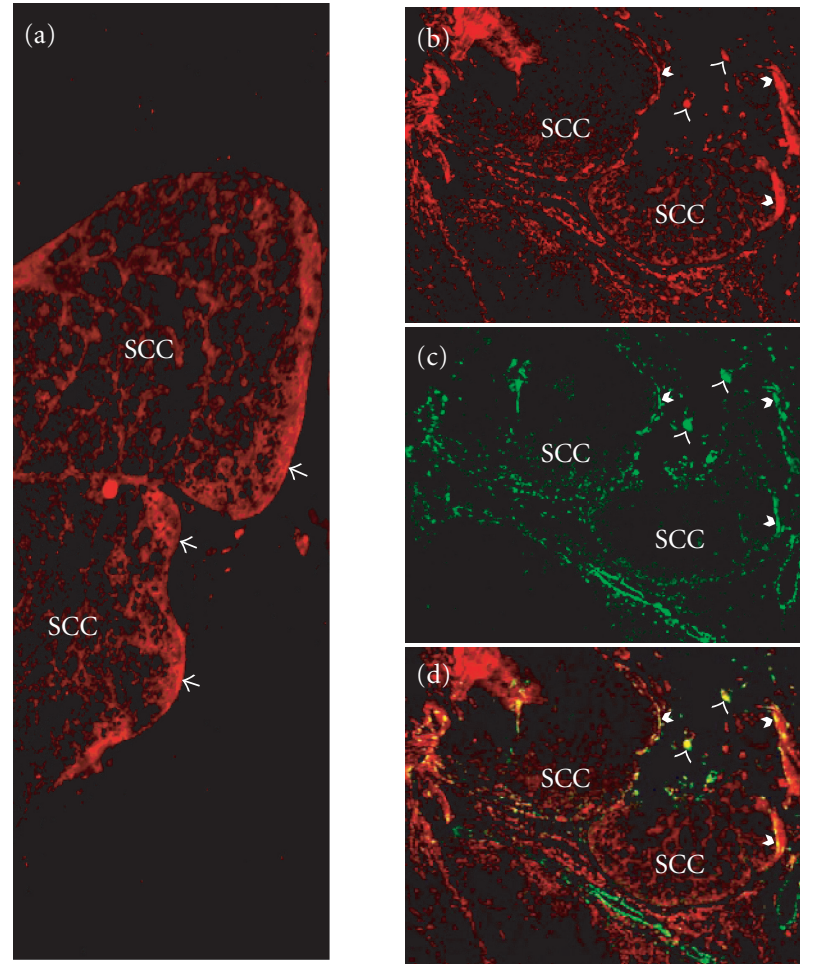

FIGURE 4: Sections of an early invasive human squamous cell carcinoma (SCC) were stained for PAI-1 (red) and $\alpha$-smooth muscle actin (green). (a) Demonstrates the localization of PAI-1 at the invasive front of the tumor (arrows). (b) (PAI-1), (c) ( $\alpha$-smooth muscle actin), and (d) (merged) illustrate the colocalization of PAI-1 with cells stained positive for $\alpha$-smooth muscle actin, a marker for myofibroblasts. Barbed arrows indicate PAI- $1 / \alpha$-SMA at the tumor perimeter, while arrow heads depict PAI- $1 / \alpha$-SMA in the stroma.

\section{TGF- $\beta 1$ /EGFR PATHWAY INTEGRATION IN PAI-1 EXPRESSION CONTROL}

Recent studies revealed a more complicated, cooperative interaction between intracellular events orchestrated by TGF$\beta 1$-activated pathways and the EGFR, which specifically lead to epithelial tumor plasticity. PAI-1 induction in response to TGF- $\beta 1$ involves a complex network of signaling intermediates and requires the activities of the mitogen-activated extracellular kinase (MEK), p2 $1^{r a s}$, and pp60 $60^{\mathrm{c}-s r}$ in addition to the EGFR [66]. pp60 ${ }^{\mathrm{c}-s r c}$ is, in fact, a critical intermediate in a TGF- $\beta 1$-initiated transduction cascade leading to MEK signaling, PAI-1 transcription, and subsequent phenotypic responses [66-70] (Figure 7). The $\operatorname{src}$ family kinase inhibitor PP1 and dominant-negative pp $60^{\mathrm{c}-s r c}$ constructs effectively attenuate TGF- $\beta 1$-induced PAI- 1 expression in $\mathrm{Ha}$ CaT cells [66], confirming the generality of src kinase involvement in PAI-1 gene regulation. While the actual mechanism underlying TGF- $\beta 1$-associated pp60 $60^{\mathrm{c}-s r c}$ kinase stimulation remains to be determined, the TGF- $\beta 1$-dependent
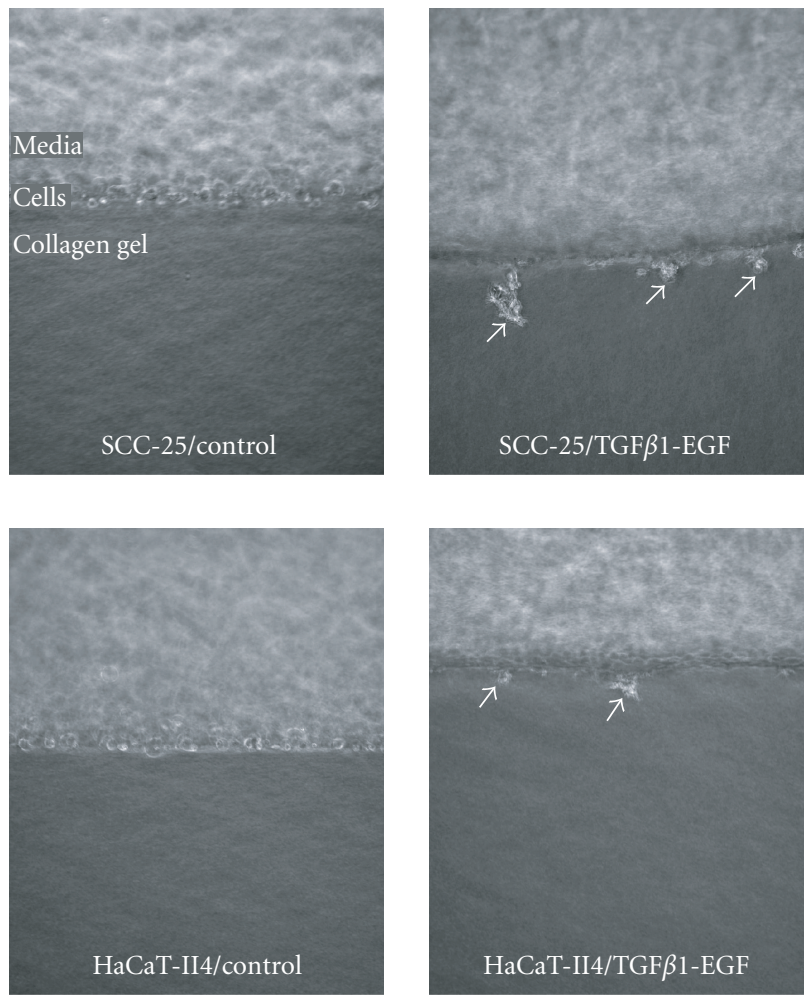

FIgUre 5: HaCaT-II4 cells invade collagen gels following costimulation with TGF- $\beta 1$ and EGF. HaCaT-II4 or SCC- 25 cells were seeded in serum-free advanced DMEM (GIBCO) onto collagen gels that had been polymerized in OptiCell tissue culture chambers. Twenty four hours later, cells were stimulated with a combination of TGF$\beta 1(1 \mathrm{ng} / \mathrm{mL})$ and EGF $(10 \mathrm{ng} / \mathrm{mL})$ under serum-free conditions and allowed to incubate for 48 hours. Pictures were taken at X10 magnification using an IX70 Olympus microscope and ImageProPlus software.

release of EGFR ligands HB-EGF and/or TGF- $\alpha$ appears to involve MMP-directed cleavage of EGF-like precursors resulting in EGFR activation [71-73]. Alternatively, formation of integrin/FAK/p130 cas/EGFR complexes in response to TGF- $\beta 1$ may result in ligand-independent EGFR mobilization and $\beta$ increased pp60 ${ }^{c-s r c}$ activity [74-76]. Subsequent changes in gene programming likely reflect the particular src-dependent MAP kinase pathways impacted. src kinases, for example, can phosphorylate the raf-1 kinase either directly or as part of a CNK1 scaffold complex, resulting in $s r c$-dependent ERK activation [77-79]. Indeed, the effective blockade of TGF- $\beta 1$-stimulated ERK1/2 phosphorylation and PAI-1 transcription by PP1 as well as the EGFR inhibitor AG1478 (Figure 7) and the requirement for MEKERK signaling for the full inductive effect of TGF- $\beta 1$, suggests that pp60 ${ }^{\mathrm{c}-s r c}$ may regulate MEK-ERK-dependent PAI-1 expression via EGFR activation at the Y845 site $[66,67,75]$.

The continued definition of specific molecular mechanisms underlying control of tumor progression genes is an essential element in the ultimate design of targeted, clinically 


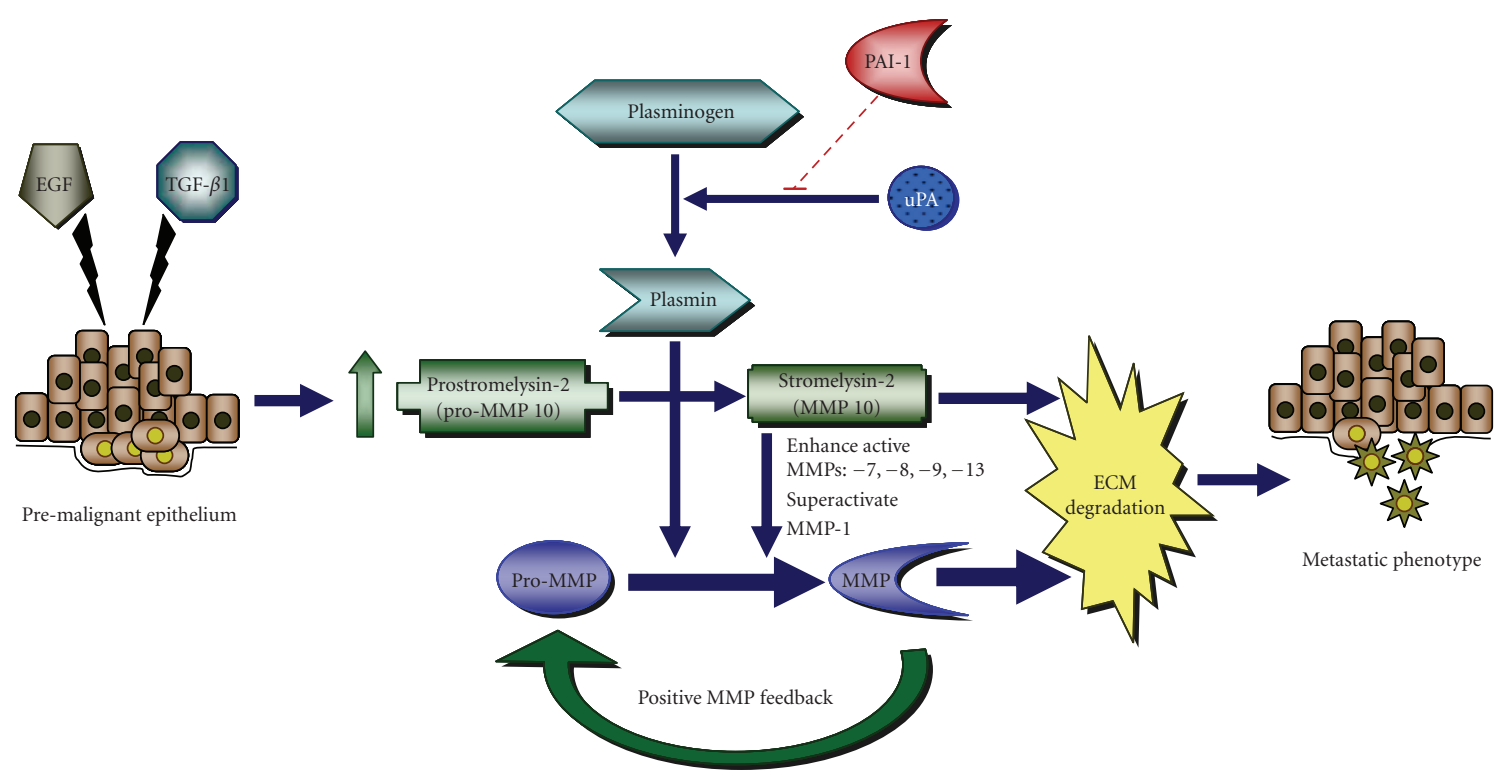

FIGURE 6: Proposed model illustrating the potential effects of TGF- $\beta 1 /$ EGF stimulated upregulation of MMP-10 and PAI- 1 on premalignant epithelial cells. (described in text).

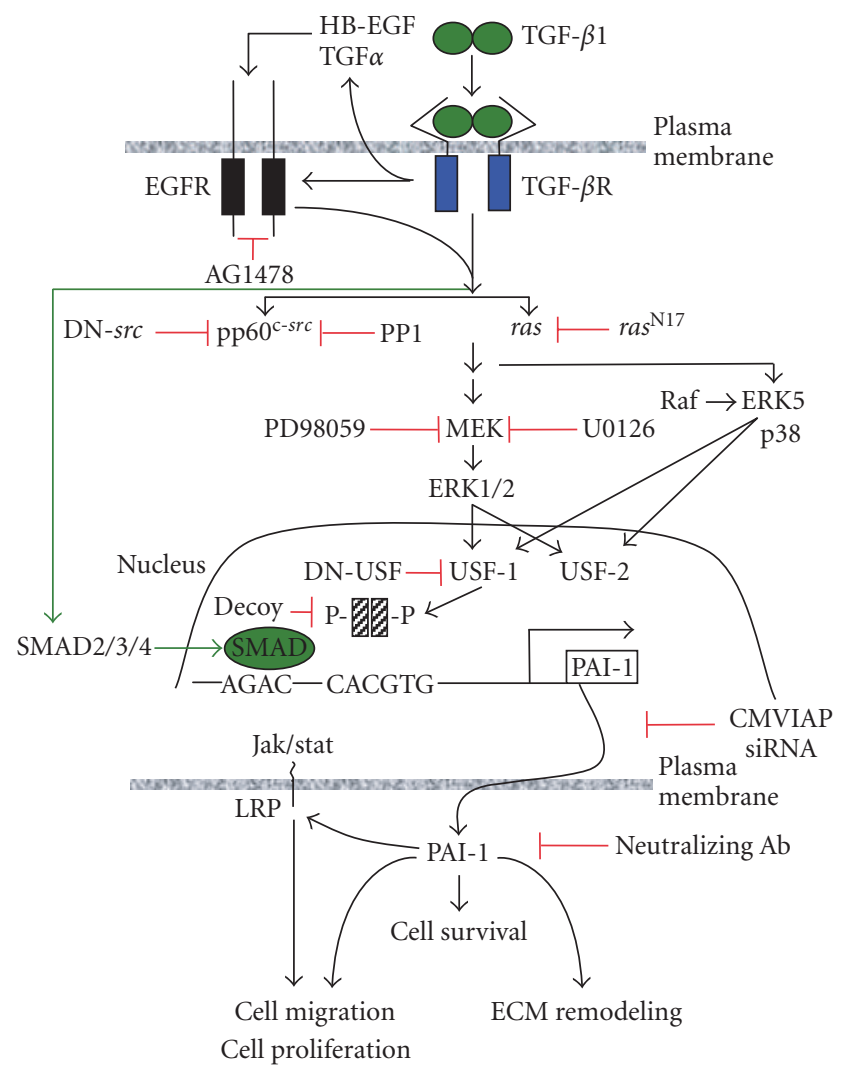

FIgURe 7: The PAI-1 expression control network. TGF- $\beta 1$ can signal alone to MEK as well as transactivate the EGFR. This cascade requires the participation of $\mathrm{pp}^{\mathrm{c}} \mathrm{0}^{\mathrm{c}-\mathrm{src}}$ and ras. The downstream-activated MAP kinases (ERKs, p38) phosphorylate, and thereby, regulate the activity of specific transcription factors (e.g., members of the USF family) that are known to impact PAI-1 gene control [13]. PAI-1 expression, in turn, affects cell survival, migration, and matrix remodeling as part of the program of epithelial plasticity. Inhibitors of PAI-1 expression or function are shown in red and represent potential therapeutic target points. 
relevant, options for treatment of human cutaneous SCC. Indeed, the emerging appreciation that cooperative EGFR signaling is an essential aspect of TGF- $\beta 1$-stimulated PAI1 expression provides novel insights to the impact of TGF$\beta 1$ in late-stage human tumor progression and underscores the potential diversity of new molecular targets that can be exploited for therapeutic benefit. Refining the current understanding of PAI-1 gene regulation, as well as its signaling pathways, may lead to the design of transcription-focused "therapeutics" to manage human cutaneous malignancies.

\section{ACKNOWLEDGMENT}

This research is supported by NIH Grants GM57242 and HL07194.

\section{REFERENCES}

[1] M. J. Eide and M. A. Weinstock, "Epidemiology of skin cancer," in Cancer of the Skin, D. S. Rigel, R. J. Friedman, L. M. Dzubow, D. S. Reintgen, J.-C. Bystryn, and R. Marks, Eds., pp. 47-60, Elsevier, Philadelphia, Pa, USA, 2005.

[2] A. Dlugosz, G. Merlino, and S. H. Yuspa, "Progress in cutaneous cancer research," Journal of Investigative Dermatology Symposium Proceedings, vol. 7, no. 1, pp. 17-26, 2002.

[3] P. Boukamp, "UV-induced skin cancer: similaritiesvariations," Journal of the German Society of Dermatology, vol. 3, no. 7, pp. 493-503, 2005.

[4] M. Dans and S. S. Fakharzadeh, "Genetic basis of skin cancer," in Cancer of the Skin, D. S. Rigel, R. J. Friedman, L. M. Dzubow, D. S. Reintgen, J.-C. Bystryn, and R. Marks, Eds., pp. 15-27, Elsevier, Philadelphia, Pa, USA, 2005.

[5] B. R. Smoller, "Squamous cell carcinoma: from precursor lesions to high-risk variants," Modern Pathology, vol. 19, supplement 2, pp. S88-S92, 2006.

[6] K. Y. Tsai and H. Tsao, "The genetics of skin cancer," American Journal of Medical Genetics-Part C: Seminars in Medical Genetics, vol. 131 C, no. 1, pp. 82-92, 2004.

[7] R. J. Akhurst and A. Balmain, "Genetic events and the role of TGF $\beta$ in epithelial tumour progression," Journal of Pathology, vol. 187, no. 1, pp. 82-90, 1999.

[8] W. Cui, D. J. Fowlis, S. Bryson, et al., "TGF $\beta 1$ inhibits the formation of benign skin tumors, but enhances progression to invasive spindle carcinomas in transgenic mice," Cell, vol. 86, no. 4, pp. 531-542, 1996.

[9] G. Portella, S. A. Cumming, J. Liddell, et al., "Transforming growth factor $\beta$ is essential for spindle cell conversion of mouse skin carcinoma in vivo: implications for tumor invasion," Cell Growth and Differentiation, vol. 9, no. 5, pp. 393404, 1998.

[10] R. Derynck, R. J. Akhurst, and A. Balmain, "TGF- $\beta$ signaling in tumor suppression and cancer progression," Nature Genetics, vol. 29, no. 2, pp. 117-129, 2001.

[11] C. Go, P. Li, and X.-J. Wang, "Blocking transforming growth factor $\beta$ signaling in transgenic epidermis accelerates chemical carcinogenesis: a mechanism associated with increased angiogenesis," Cancer Research, vol. 59, no. 12, pp. 2861-2868, 1999.

[12] G. Han, S.-L. Lu, A. G. Li, et al., "Distinct mechanisms of TGF- $\beta 1$-mediated epithelial-to-mesenchymal transition and metastasis during skin carcinogenesis," Journal of Clinical Investigation, vol. 115, no. 7, pp. 1714-1723, 2005.
[13] R. R. Allen and P. J. Higgins, "Plasminogen activator inhibitor type-1 expression and the pathophysiology of TGF- $\beta 1$ incuced epithelial-to-mesechymal transition," Recent Research Developments in Physiology, vol. 2, pp. 355-366, 2004.

[14] O. Rho, L. M. Beltran, I. B. Gimenez-Conti, and J. DiGiovanni, "Altered expression of the epidermal growth factor receptor and transforming growth factor- $\alpha$ during multistage skin carcinogenesis in SENCAR mice," Molecular Carcinogenesis, vol. 11, no. 1, pp. 19-28, 1994.

[15] S. H. Yuspa, "The pathogenesis of squamous cell cancer: lessons learned from studies of skin carcinogenesis," Journal of Dermatological Science, vol. 17, no. 1, pp. 1-7, 1998.

[16] P. O-Charoenrat, P. H. Rhys-Evans, H. Modjtahedi, W. Court, G. Box, and S. Eccles, "Overexpression of epidermal growth factor receptor in human head and neck squamous carcinoma cell lines correlates with matrix metalloproteinase-9 expression and in vitro invasion," International Journal of Cancer, vol. 86, no. 3, pp. 307-317, 2000.

[17] P. O-charoenrat, P. H. Rhys-Evans, D. J. Archer, and S. A. Eccles, "C-erbB receptors in squamous cell carcinomas of the head and neck: clinical significance and correlation with matrix metalloproteinases and vascular endothelial growth factors," Oral Oncology, vol. 38, no. 1, pp. 73-80, 2002.

[18] N. Moghal and P. W. Sternberg, "Multiple positive and negative regulators of signaling by the EGF-receptor," Current Opinion in Cell Biology, vol. 11, no. 2, pp. 190-196, 1999.

[19] J. Zavadil and E. P. Bottinger, "TGF- $\beta$ and epithelial-tomesenchymal transitions," Oncogene, vol. 24, no. 37, pp. 57645774, 2005.

[20] J. Zavadil, M. Bitzer, D. Liang, et al., "Genetic programs of epithelial cell plasticity directed by transforming growth factor$\beta$," Proceedings of the National Academy of Sciences of the United States of America, vol. 98, no. 12, pp. 6686-6691, 2001.

[21] T. A. Lehman, R. Modali, P. Boukamp, et al., "p53 mutations in human immortalized epithelial cell lines," Carcinogenesis, vol. 14, no. 5, pp. 833-839, 1993.

[22] C. E. Wilkins-Port, J. Freytag, and P. J. Higgins, "TGF $\beta 1 /$ EGF modulate pericellular proteolysis by stimulating collagenolytic activity in pre-malignant human epidermal keratinocytes," in Proceedings of the Epithelial Mesenchymal Transition (EMT) Conference, vol. 56, p. 31, Vancouver, British Columbia, Canada, October 2005.

[23] C. E. Wilkins-Port and P. J. Higgins, "Regulation of extracellular matrix remodeling following TGF $\beta 1 /$ EGF stimulated EMT in human pre-malignant keratinocytes," to appear in Cells Tissues Organs.

[24] R. R. Isseroff and D. B. Rifkin, "Plasminogen is present in the basal layer of the epidermis," Journal of Investigative Dermatology, vol. 80, no. 4, pp. 297-299, 1983.

[25] H. R. Lijnen, "Matrix metalloproteinases and cellular fibrinolytic activity," Biochemistry, vol. 67, no. 1, pp. 92-98, 2002.

[26] P. A. Andreasen, L. Kjøller, L. Christensen, and M. J. Duffy, "The urokinase-type plasminogen activator system in cancer metastasis: a review," International Journal of Cancer, vol. 72, no. 1, pp. 1-22, 1997.

[27] B. Hundsdorfer, H. F. Zeilhofer, K. P. Bock, P. Dettmar, M. Schmitt, and H. H. Horch, "The prognostic importance of urokinase type plasminogen activators (uPA) and plasminogen activator inhibitors (PAI-1) in primary resection of oral squamous cell carcinoma," Mund Kiefer Grsichtschir, vol. 8, no. 3, pp. 173-179, 2004. 
[28] E. Bacharach, A. Itin, and E. Keshet, "Apposition-dependent induction of plasminogen activator inhibitor type 1 expression: a mechanism for balancing pericellular proteolysis during angiogenesis," Blood, vol. 92, no. 3, pp. 939-945, 1998.

[29] K. Bajou, V. Masson, R. D. Gerard, et al., "The plasminogen activator inhibitor PAI-1 controls in vivo tumor vascularization by interaction with proteases, not vitronectin: implications for antiangiogenic strategies," Journal of Cell Biology, vol. 152, no. 4, pp. 777-784, 2001.

[30] K. Bajou, A. Noël, R. D. Gerard, et al., "Absence of host plasminogen activator inhibitor 1 prevents cancer invasion and vascularization," Nature Medicine, vol. 4, no. 8, pp. 923-928, 1998.

[31] Y.-J. Chen, S.-C. Lin, T. Kao, et al., "Genome-wide profiling of oral squamous cell carcinoma," Journal of Pathology, vol. 204, no. 3, pp. 326-332, 2004.

[32] P. Lindberg, A. Larsson, and B. S. Nielsen, "Expression of plasminogen activator inhibitor-1, urokinase receptor and laminin $\gamma$-2 chain is an early coordinated event in incipient oral squamous cell carcinoma," International Journal of Cancer, vol. 118, no. 12, pp. 2948-2956, 2006.

[33] E. Vairaktaris, C. Yapijakis, Z. Serefoglou, et al., "Plasminogen activator inhibitor-1 polymorphism is associated with increased risk for oral cancer," Oral Oncology, vol. 42, no. 9, pp. 888-892, 2006.

[34] L. Christensen, A. C. Wiborg Simonsen, C. W. Heegaard, S. K. Moestrup, J. A. Andersen, and P. A. Andreasen, "Immunohistochemical localization of urokinase-type plasminogen activator, type-1 plasminogen-activator inhibitor, urokinase receptor and $\alpha_{2}$-macroglobulin receptor in human breast carcinomas," International Journal of Cancer, vol. 66, no. 4, pp. 441-452, 1996.

[35] M. Illemann, U. Hansen, H. J. Nielsen, et al., "Leading-edge myofibroblasts in human colon cancer express plasminogen activator inhibitor-1," American Journal of Clinical Pathology, vol. 122, no. 2, pp. 256-265, 2004.

[36] B. V. Offersen, B. S. Nielsen, G. Høyer-Hansen, et al., "The myofibroblast is the predominant plasminogen activator inhibitor-1-expressing cell type in human breast carcinomas," American Journal of Pathology, vol. 163, no. 5, pp. 1887-1899, 2003.

[37] D. Chin, G. M. Boyle, P. G. Parsons, and W. B. Coman, "What is transforming growth factor-beta (TGF- $\beta$ )?" British Journal of Plastic Surgery, vol. 57, no. 3, pp. 215-221, 2004.

[38] C. H. Streuli, C. Schmidhauser, M. Kobrin, M. J. Bissell, and R. Derynck, "Extracellular matrix regulates expression of the TGF- $\beta 1$ gene," Journal of Cell Biology, vol. 120, no. 1, pp. 253260, 1993.

[39] T. M. Vollberg, M. D. George, and A. M. Jetten, "Induction of extracellular matrix gene expression in normal human keratinocytes by transforming growth factor $\beta$ is altered by cellular differentiation," Experimental Cell Research, vol. 193, no. 1, pp. 93-100, 1991.

[40] N. E. Wikner, J. T. Elder, K. A. Persichitte, P. Mink, and R. A. F. Clark, "Transforming growth factor- $\beta$ modulates plasminogen activator activity and plasminogen activator inhibitor type-1 expression in human keratinocytes in vitro," Journal of Investigative Dermatology, vol. 95, no. 5, pp. 607-613, 1990.

[41] K. Ahokas, J. Lohi, S. A. Illman, et al., "Matrix metalloproteinase-21 is expressed epithelially during development and in cancer and is up-regulated by transforming growth factor- $\beta 1$ in Keratinocytes," Laboratory Investigation, vol. 83, no. 12, pp. 1887-1899, 2003.

[42] N. Johansson, J. Westermarck, S. Leppä, et al., "Collagenase 3 (matrix metalloproteinase 13) gene expression by HaCaT keratinocytes is enhanced by tumor necrosis factor $\alpha$ and transforming growth factor $\beta$," Cell Growth and Differentiation, vol. 8, no. 2, pp. 243-250, 1997.

[43] E.-S. Kim, M.-S. Kim, and A. Moon, "TGF- $\beta$-induced upregulation of MMP-2 and MMP-9 depends on p38 MAPK, but not ERK signaling in MCF10A human breast epithelial cells," International Journal of Oncology, vol. 25, no. 5, pp. 1375-1382, 2004.

[44] E.-S. Kim, M.-S. Kim, and A. Moon, "Transforming growth factor (TGF)- $\beta$ in conjunction with $\mathrm{H}$-ras activation promotes malignant progression of MCF10A breast epithelial cells," $C y$ tokine, vol. 29, no. 2, pp. 84-91, 2005.

[45] H.-S. Kim, T. Shang, Z. Chen, S. C. Pflugfelder, and D.-Q. Li, "TGF- $\beta 1$ stimulates production of gelatinase (MMP-9), collagenases (MMP-1, -13) and stromelysins (MMP-3, -10, -11) by human corneal epithelial cells," Experimental Eye Research, vol. 79, no. 2, pp. 263-274, 2004.

[46] M. Madlener, C. Mauch, W. Conca, M. Brauchle, W. C. Parks, and S. Werner, "Regulation of the expression of stromelysin2 by growth factors in keratinocytes: implications for normal and impaired wound healing," Biochemical Journal, vol. 320, no. 2, pp. 659-664, 1996.

[47] H. G. Munshi, Y. I. Wu, S. Mukhopadhyay, et al., "Differential regulation of membrane type 1-matrix metalloproteinase activity by ERK 1/2- and p38 MAPK-modulated tissue inhibitor of metalloproteinases 2 expression controls transforming growth factor- $\beta 1$-induced pericellular collagenolysis," Journal of Biological Chemistry, vol. 279, no. 37, pp. 39042-39050, 2004.

[48] M. J. Newman, "Transforming growth factor beta and the cell surface in tumor progression," Cancer and Metastasis Reviews, vol. 12, no. 3-4, pp. 239-254, 1993.

[49] A. B. Roberts, B. K. McCune, and M. B. Sporn, "TGF- $\beta$ : regulation of extracellular matrix," Kidney International, vol. 41, no. 3, pp. 557-559, 1992.

[50] A. B. Roberts and L. M. Wakefield, "The two faces of transforming growth factor $\beta$ in carcinogenesis," Proceedings of the National Academy of Sciences of the United States of America, vol. 100, no. 15, pp. 8621-8623, 2003.

[51] J. A. Wright, E. A. Turley, and A. H. Greenberg, "Transforming growth factor $\beta$ and fibroblast growth factor as promoters of tumor progression to malignancy," Critical Reviews in Oncogenesis, vol. 4, no. 5, pp. 473-492, 1993.

[52] T. Sato, M. Iwai, T. Sakai, et al., "Enhancement of membranetype 1-matrix metalloproteinase (MT1-MMP) production and sequential activation of progelatinase $\mathrm{A}$ on human squamous carcinoma cells co-cultured with human dermal fibroblasts," British Journal of Cancer, vol. 80, no. 8, pp. 1137-1143, 1999.

[53] B. D. Sudbeck, P. Baumann, G. J. Ryan, et al., "Selective loss of PMA-stimulated expression of matrix metalloproteinase 1 in $\mathrm{HaCaT}$ keratinocytes is correlated with the inability to induce mitogen-activated protein family kinases," Biochemical Journal, vol. 339, no. 1, pp. 167-175, 1999.

[54] L. L. Chen, R. Narayanan, M. S. Hibbs, et al., "Altered epidermal growth factor signal transduction in activated Ha-ras- 
transformed human keratinocytes," Biochemical and Biophysical Research Communications, vol. 193, no. 1, pp. 167-174, 1993.

[55] P. O-charoenrat, P. H. Rhys-Evans, and S. A. Eccles, "Expression of matrix metalloproteinases and their inhibitors correlates with invasion and metastasis in squamous cell carcinoma of the head and neck," Archives of Otolaryngology-Head of Neck Surgery, vol. 127, no. 7, pp. 813-820, 2001.

[56] L. J. Windsor, H. Grenett, B. Birkedal-Hansen, M. K. Bodden, J. A. Engler, and H. Birkedal-Hansen, "Cell type-specific regulation of SL-1 and SL-2 genes. Induction of the SL-2 gene but not the SL-1 gene by human keratinocytes in response to cytokines and phorbolesters," Journal of Biological Chemistry, vol. 268, no. 23, pp. 17341-17347, 1993.

[57] S. Chakraborti, M. Mandal, S. Das, A. Mandal, and T. Chakraborti, "Regulation of matrix metalloproteinases: an overview," Molecular and Cellular Biochemistry, vol. 253, no. 12, pp. 269-285, 2003.

[58] N. H. Cho, K. P. Hong, S. H. Hong, S. Kang, K. Y. Chung, and S. H. Cho, "MMP expression profiling in recurred stage IB lung cancer," Oncogene, vol. 23, no. 3, pp. 845-851, 2004.

[59] J. H. Gill, I. G. Kirwan, J. M. Seargent, et al., "MMP-10 is overexpressed, proteolytically active, and a potential target for therapeutic intervention in human lung carcinomas," Neoplasia, vol. 6, no. 6, pp. 777-785, 2004.

[60] M. Krampert, W. Bloch, T. Sasaki, et al., "Activities of the matrix metalloproteinase stromelysin-2 (MMP-10) in matrix degradation and keratinocyte organization in wounded skin," Molecular Biology of the Cell, vol. 15, no. 12, pp. 5242-5254, 2004.

[61] O. Rechardt, O. Elomaa, M. Vaalamo, et al., "Stromelysin-2 is upregulated during normal wound repair and is induced by cytokines," Journal of Investigative Dermatology, vol. 115, no. 5, pp. 778-787, 2000.

[62] U. Impola, V. J. Uitto, J. Hietanen, et al., "Differential expression of matrilysin-I (MMP-7), $92 \mathrm{kD}$ gelatinase (MMP-9), and metalloelastase (MMP-12) in oral verrucous and squamous cell cancer," Journal of Pathology, vol. 202, no. 1, pp. 14-22, 2004.

[63] E. Kerkelä, R. Ala-aho, L. Jeskanen, et al., "Differential patterns of stromelysin-2 (MMP-10) and MT1-MMP (MMP-14) expression in epithelial skin cancers," British Journal of Cancer, vol. 84, no. 5, pp. 659-669, 2001.

[64] R. Mathew, R. Khanna, R. Kumar, M. Mathur, N. K. Shukla, and R. Ralhan, "Stromelysin-2 overexpression in human esophageal squamous cell carcinoma: potential clinical implications," Cancer Detection and Prevention, vol. 26, no. 3, pp. 222-228, 2002.

[65] P. J. Higgins, “TGF- $\beta 1$-stimulated $21^{\text {ras }}$-ERK signaling regulates expression of the angiogenic SERPIN PAI-1," Recent Research Developments in Biochemistry, vol. 7, pp. 31-45, 2006.

[66] S. M. Kutz, C. E. Higgins, R. Samarakoon, et al., “TGF- $\beta 1$ induced PAI-1 expression is E box/USF-dependent and requires EGFR signaling," Experimental Cell Research, vol. 312, no. 7, pp. 1093-1105, 2006.

[67] R. Samarakoon, C. E. Higgins, S. P. Higgins, S. M. Kutz, and P. J. Higgins, "Plasminogen activator inhibitor type-1 gene expression and induced migration in TGF- $\beta 1$-stimulated smooth muscle cells is pp $60^{c-s r c} /$ MEK-dependent," Journal of Cellular Physiology, vol. 204, no. 1, pp. 236-246, 2005.

[68] P. P.-C. Hu, X. Shen, D. Huang, Y. Liu, C. Counter, and X.F. Wang, "The MEK pathway is required for stimulation of
p21(WAF1/CIP1) by transforming growth factor- $\beta$," Journal of Biological Chemistry, vol. 274, no. 50, pp. 35381-35387, 1999.

[69] M. Sato, K. Kawai-Kowase, H. Sato, et al., "c-Src and hydrogen peroxide mediate transforming growth factor- $\beta 1$-induced smooth muscle cell-gene expression in 10T1/2 cells," Arteriosclerosis, Thrombosis, and Vascular Biology, vol. 25, no. 2, pp. 341-347, 2005.

[70] H. Sato, M. Sato, H. Kanai, et al., "Mitochondrial reactive oxygen species and c-Src play a critical role in hypoxic response in vascular smooth muscle cells," Cardiovascular Research, vol. 67, no. 4, pp. 714-722, 2005.

[71] F. Viñals and J. Pouysségur, "Transforming growth factor $\beta 1$ (TGF- $\beta 1$ ) promotes endothelial cell survival during in vitro angiogenesis via an autocrine mechanism implicating TGF- $\alpha$ signaling," Molecular and Cellular Biology, vol. 21, no. 21, pp. 7218-7230, 2001.

[72] J. Guerrero, J. F. Santibañez, A. González, and J. Martínez, "EGF receptor transactivation by urokinase receptor stimulus through a mechanism involving Src and matrix metalloproteinases," Experimental Cell Research, vol. 292, no. 1, pp. 201208, 2004.

[73] Y. Uchiyama-Tanaka, H. Matsubara, Y. Mori, et al., "Involvement of HB-EGF and EGF receptor transactivation in TGF$\beta$-mediated fibronectin expression in mesangial cells," Kidney International, vol. 62, no. 3, pp. 799-808, 2002.

[74] L. Moro, L. Dolce, S. Cabodi, et al., "Integrin-induced epidermal growth factor (EGF) receptor activation requires c-Src and p130Cas and leads to phosphorylation of specific EGF receptor tyrosines," Journal of Biological Chemistry, vol. 277, no. 11, pp. 9405-9414, 2002.

[75] J. S. Biscardi, M.-C. Maa, D. A. Tice, M. E. Cox, T.-H. Leu, and S. J. Parsons, "c-Src-mediated phosphorylation of the epidermal growth factor receptor on tyr ${ }^{845}$ and $\operatorname{tyr}^{1101}$ is associated with modulation of receptor function," Journal of Biological Chemistry, vol. 274, no. 12, pp. 8335-8343, 1999.

[76] C. K. Miranti and J. S. Brugge, "Sensing the environment: a historical perspective on integrin signal transduction," Nature Cell Biology, vol. 4, no. 4, pp. E83-E90, 2002.

[77] A. Alavi, J. D. Hood, R. Frausto, D. G. Stupack, and D. A. Cheresh, "Role of Raf in vascular protection from distinct apoptotic stimuli," Science, vol. 301, no. 5629, pp. 94-96, 2003.

[78] F. Chang, L. S. Steelman, J. T. Lee, et al., "Signal transduction mediated by the Ras/Raf/MEK/ERK pathway from cytokine receptors to transcription factors: potential targeting for therapeutic intervention," Leukemia, vol. 17, no. 7, pp. 1263-1293, 2003.

[79] A. Ziogas, K. Moelling, and G. Radziwill, "CNK1 is a scaffold protein that regulates Src-mediated Raf-1 activation," Journal of Biological Chemistry, vol. 280, no. 25, pp. 24205-24211, 2005. 

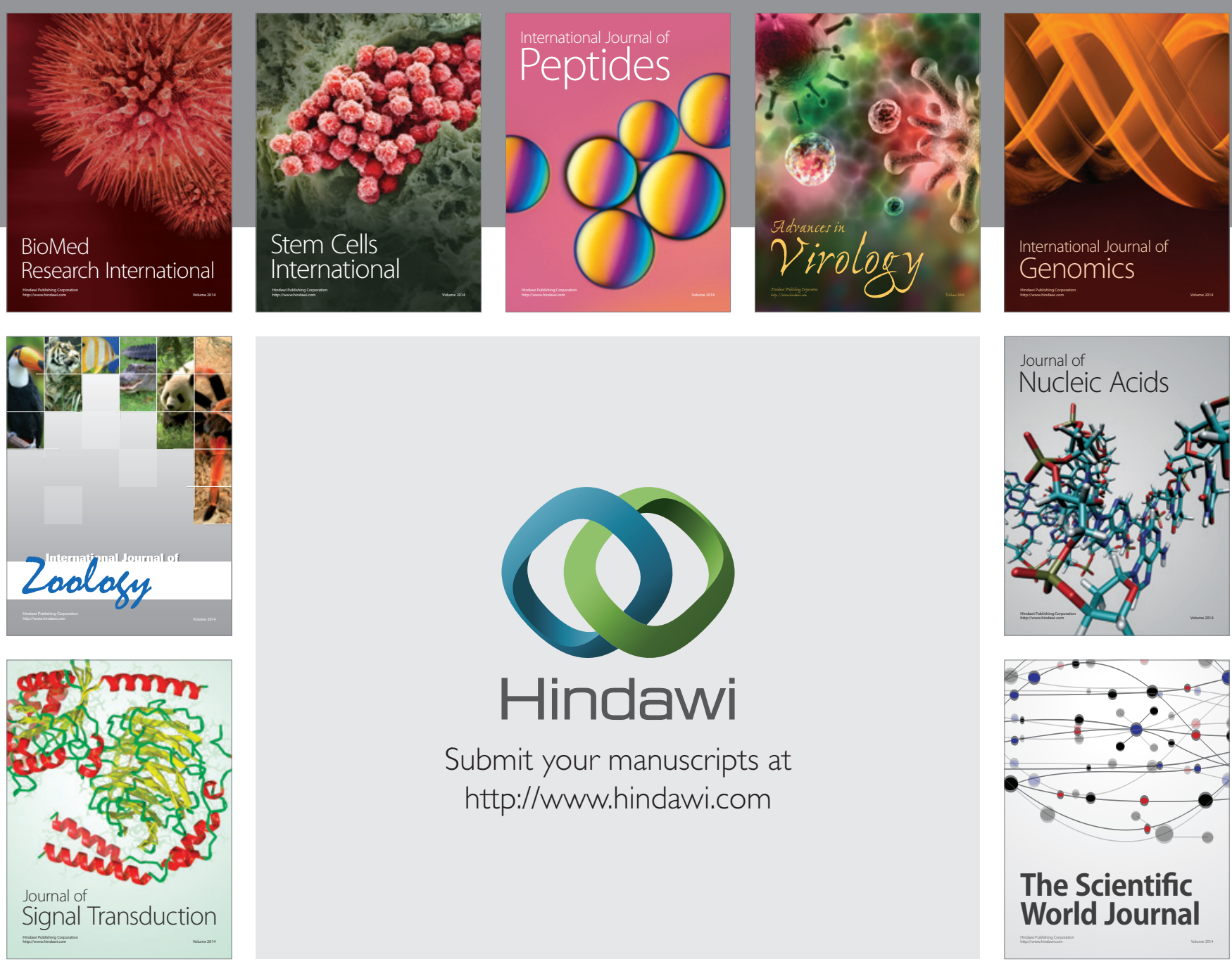

Submit your manuscripts at

http://www.hindawi.com
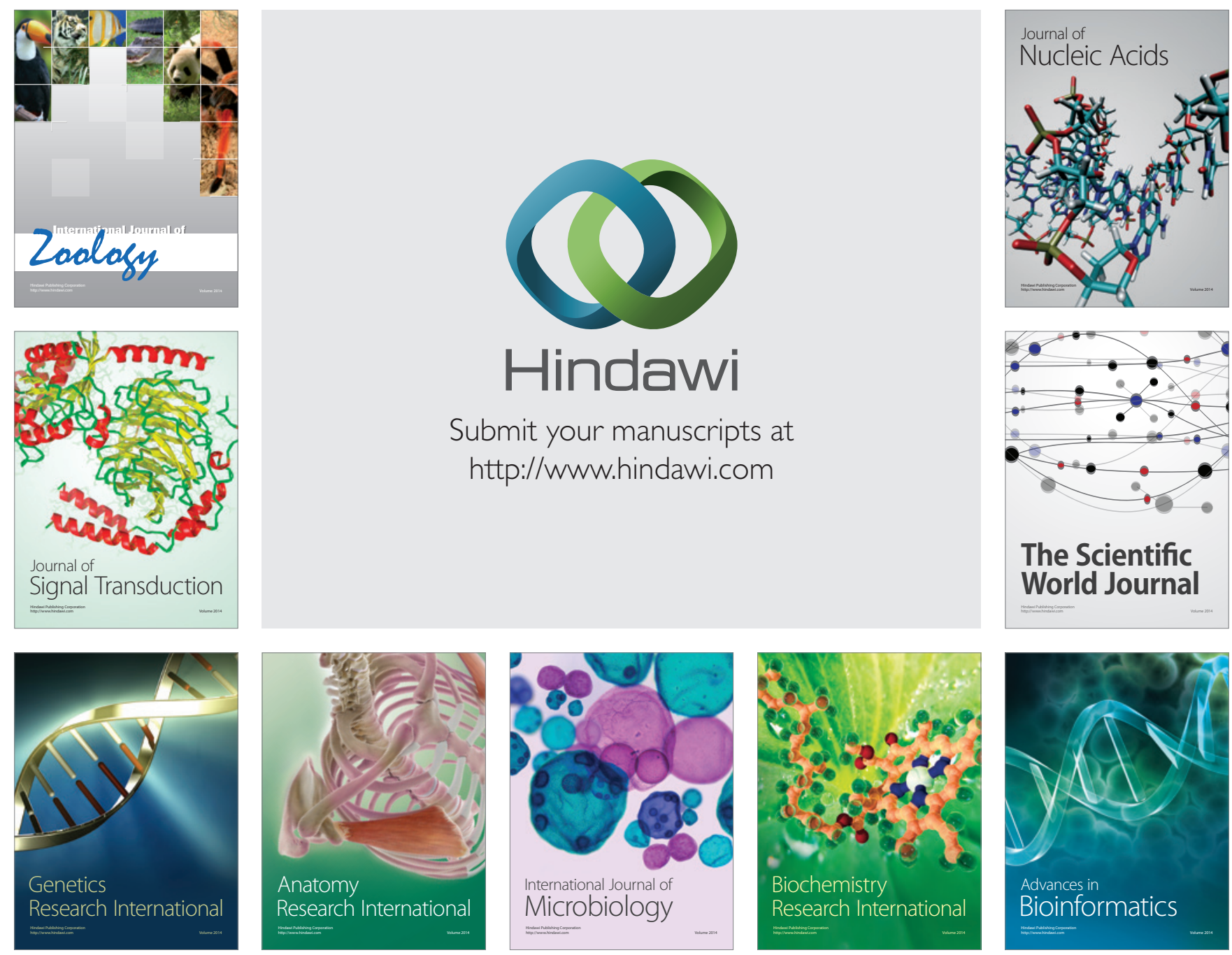

The Scientific World Journal
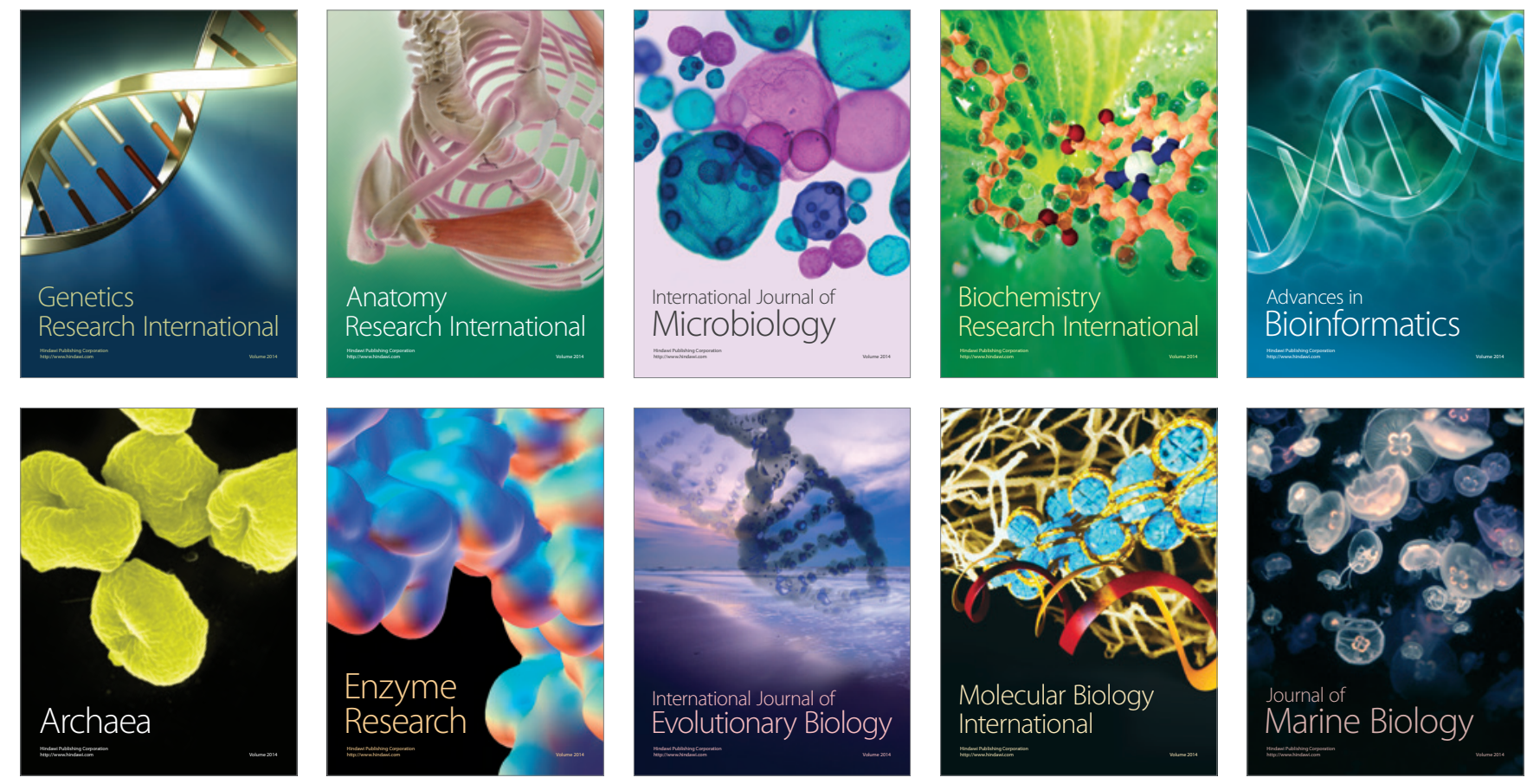